\title{
EFFECTIVENESS OF MUCOSAL VIBRATION ON PAIN PERCEPTION DURING INFERIOR ALVEOLAR NERVE BLOCK ADMINISTRATION IN CHILDREN (Randomized Controlled Clinical Trial)
}

\author{
Passant H. Hassanein ${ }^{1 *}$, Amani Khalil ${ }^{2}$, Dalia M. Talaat ${ }^{3}$
}

\begin{abstract}
INTRODUTION: Pain is a complex experience that is affected by factors such as gender, stress, anxiety and cognitions. Pain control in dental clinic is the major concern especially when dealing with children. It is mandatory to use local anesthesia to keep any discomfort or pain to the minimum. Unfortunately, there is discomfort associated with injection especially inferior alveolar nerve block (IANB) as it is considered as one of the most painful injections.

OBJECTIVES: The purpose of this study was to compare the effectiveness of DentalVibe (DV) and 20\% benzocaine gel on pain perception experienced by boys and girls during inferior alveolar nerve block administration.

MATERIALS AND METHODS: This study was a cross over randomized controlled clinical trial where 60 children (30 males and 30 females) aged 5-7 years were selected from the outpatient clinic of Pediatric Dentistry and Public Health Department, Faculty of Dentistry, Alexandria University after securing necessary consents. Children with bilateral mandibular molars indicated for pulpotomy treatment were included in the study. They were divided into 2 groups. During the first visit, IANB was performed either with vibration using DV at the injection side or after the application of $20 \%$ benzocaine gel. After two weeks, the alternative technique was used (cross-over). In each visit, subjective pain was evaluated using the Wong-Baker Faces pain rating scale (PRS).

RESULTS: Wong Baker Faces PRS showed a statistically significant difference between DV and benzocaine gel groups in favor of DV (P $\leq$ 0.001); where DV group scored lower mean pain value $(0.80 \pm 1.34)$ while benzocaine gel scored $2.60 \pm 3.22$. Regarding gender influence, no significant difference was reported in the pain scores of the two pain reduction methods.

CONCLUSION: The use of the DV injection system reduced the pain associated with IANB administration in children. Regarding gender, it was found to have no influence on pain perception.

KEYWORDS: Inferior alveolar nerve block, DentalVibe, Gender pain sensitivity, Wong-Baker Faces pain rating scale.
\end{abstract}

\footnotetext{
${ }^{1}$ Demonstrator at pediatric dentistry and dental public health department, Alexandria university.

${ }^{2}$ Professor at pediatric dentistry and dental public health department, Alexandria university.

${ }^{3}$ Associate professor at pediatric dentistry and dental public health department, Alexandria university.
}

*Corresponding author

passant.metwally@alexu.edu.eg

\section{INTRODUCTION}

The pain experience of children during aversive medical procedures is related to personal and procedural factors. While pain is caused by a physiological process, it also has a strong cognitive component. It is a complex process with sensory and emotional aspects, and associated with a lot of factors such as stress, anxiety and gender (1). People with dental anxiety can have both exaggerated pain expectancies and pain perceptions (2-4). Pain is primarily an internal experience not directly accessible to others, children's selfreport should be the primary source of information on pain intensity when possible (5). Most children aged 5 years and older can provide meaningful self-report of pain if age appropriate tools are used (6). The subjective evaluation of pain in general, and in the dental setting in particular is significantly affected by gender (7). However, Eli et al (7) stated that pain perception is still controversial regarding gender difference in response to pain stimuli. Fillingim and Maxiner (8) in their literature review summarized that females exhibit greater sensitivity to noxious stimuli than males. Besides, Perry et al (9) found that females experienced more pain during local anesthetic injection. However, Sermet et al (10) reported contradictory results. Pain generally and associated with local anesthetic administration specifically, seems to cause more distress to patients than the actual disease process itself and may even cause patients to avoid necessary treatment. In response, clinicians try to use a variety of methods, pharmacological and nonpharmacological, in an attempt to reduce pain from injections (11-13). Recently, the concept of vibration stimuli in conjunction with local anesthetic injection has been introduced (14). Mucosal vibration, which is based on gate 
control theory, is considered a non-pharmacological technique (15). This theory proposed that activation of nonnociceptive nerve fibers, which do not transmit pain signals, can interfere with signals from pain fibers, thereby inhibiting pain, as if the spinal cord contains a neurological "gate". Mechanical stimulation to large diameter fibers (e.g., massage techniques, rubbing, pressure, acupuncture, or vibration) causes a release of inhibitory neurons that can interfere with signals from pain fibers, thereby inhibiting the pain sensation (16-18). DentalVibe (DV) is one of the vibrotactile devices used to lower the pain of local anesthetic injection. It has been introduced in an attempt to deliver vibration in a sustained frequency as a counter stimulation onto the site of injection thereby alleviating the pain (19). The device is attractive especially for children as it can be used as a retractor in the same manner as a dental mirror. It requires no modification to the traditional anesthetic protocol, including injection technique, patient positioning, and time involved. If effective, the device may represent a time-efficient, nonpharmacological technique to improve the experience of children receiving local anesthetic. Results from studies on the effect of DV are contradictory $(10,20$, 21). Moreover, few data are present regarding gender influence on pain perception using DV and benzocaine gel. Therefore, this study aimed to compare the effectiveness of DentalVibe and 20\% benzocaine gel on pain perception experienced by boys and girls during inferior alveolar nerve block administration. The null hypothesis tested was that there was no difference neither in the pain perception experienced by DV compared to benzocaine gel nor in the pain perception in both genders during inferior alveolar nerve block administration.

\section{MATERIALS AND METHODS}

This study was a crossover randomized controlled clinical trial. It was setup and reported according to the CONSORT Statement. The PICO question was: do pediatric patients aged from 5-7 years (population; P) assigned to inferior alveolar nerve block injection with the aid of Dental Vibe tool (DV) (intervention; I) in comparison to the use of $20 \%$ benzocaine gel (control; C) show the same pain perception (outcome; O). The study was approved by the Research Ethics Committee, Faculty of Dentistry, Alexandria University (\#IRB NO: 00010556 - IORG 0008839) and registered at the National Institutes of Health (\#NCT03790540). For all patients who met the inclusion criteria, a signed informed consent was obtained from the parents/ guardians prior to treatment.

\section{Eligibility criteria}

Healthy children with no previous dental history were included in the study. Their age ranged from 5-7 years. All included participants had to have bilateral mandibular molars that were indicated for pulpotomy treatment. Clinically, children who complained from provoked pain stimulated by any irritants, intermittent of short duration, relieved with over-the-counter analgesics, by removal of stimulus and without any signs or symptoms of irreversible pulpitis were involved in the study. Children that were classified as positive or definitely positive according to the Frankl Scale were also included (22). Participants with active sites of pathosis in the area of injection or any signs of irreversible pulpitis or pulp necrosis were excluded from the study. Similarly, all cases with radiographs showing periapical or bifurcation radiolucency and acute oral or facial infection (swelling and/or cellulites) were not included. Children who were allergic to local anesthesia or having a family history of allergy to local anesthesia were also excluded.

\section{Study setting and location}

Participants were recruited (from January to March 2019) from the outpatient clinic, Pediatric Dentistry and Dental Public Health Department, Faculty of Dentistry, Alexandria University, Egypt.

\section{Sample size estimation}

The minimal sample size was calculated based on a previous study conducted by Dak-Albab et al. (2016) (21). A sample size of 30 patients per group (number of groups=2) was the enough required sample to detect a standardized effect size of 0.450 change in the primary outcome (pain intensity) (23, $24)$, as statistically significant with $80 \%$ power and at a significance level of 0.05 . Sample size per group did not need to be increased to control for attrition bias (25). The sample size was calculated using G-Power 3.1.9.2 software (Universität Düsseldorf, Germany) (26).

\section{Randomization technique}

Subjects complying with the inclusion criteria were randomly assigned using a computer -generated list to one of the two groups (first visit either injection with the aid of DV tool or with $20 \%$ benzocaine gel, then the other technique was used in the second visit [crossover]). Allocation was performed by a trial independent individual and the allocation ratio was intended to be equal. For the injection side in the first visit, randomization was performed for each group using a computer -generated list to either left or right side to start with.

\section{Allocation concealment}

Each child included in the study was given a serial number that was used in the allocation. These numbers were written in identical sheets of paper with the group to which each child was allocated and placed inside opaque envelopes carrying the respective names of the children. A trial independent personnel was assigned to the role of keeping the envelopes and unfolding them only at the time of the local anesthesia injection session so that the group the child was allocated to was concealed from the outcome evaluator.

\section{Blinding}

The operator was not blinded to the type of intervention. However, the statistician was blinded to the intervention groups.

\section{Intervention}

Preliminary screening and full medical and dental history were carried out to select patients who fulfilled the inclusion criteria. The participants were examined clinically and 
radiographically to ensure that they matched the inclusion criteria. The participants were randomly allocated into two groups, whatever the first intervention they were allocated to start with; Group I: acted as experimental group $(\mathrm{N}=30)$ assigned to injection with the aid of DV tool (Bing Innovations, Boca Raton, FL, USA) and Group II: acted as control group $(\mathrm{N}=30)$ assigned to local anesthesia after application of $20 \%$ benzocaine (Dharma Research, INC. FL, USA) as a topical anesthetic gel. Each group received 2 IANB (Mepivacaine $\mathrm{HCl}$ 2\%, 1/20000 Levonordefrin, Alexandria co. for Pharmaceuticals, Alexandria, Egypt) local anesthesia with two different mucosal treatments. A wash out period of 2 weeks was included before the alternative treatment (Figure 1). Regarding the cross-over design, in the first appointment IANB was performed either with vibration using DV tool at the injection site or $20 \%$ benzocaine gel applied before local anesthetic injection. At the second appointment, which was the after 2 weeks washout period the alternative technique was used on the same patient.

Preparation of the patient prior to injection consisted of two components mental and physical (27). The anesthesia administration process was explained to all participants in the terminology they could understand. Before using the DV tool, a demonstration was performed by placing the device into direct contact with the children's nails before applying it intraorally. In the control group the benzocaine gel $20 \%$ was applied and left in contact with the soft tissue for one minute after drying the tissue using ( $2 \times 2)$ gauze to enhance its absorption (28).

For the experimental group, first the area of needle penetration was stimulated by turning on the DV tool to the oral mucosa at the site of injection. Then, five seconds following the vibration, the needle was inserted. DentalVibe continued vibrating during needle insertion and anesthetic injection (20). All dental injections were administered by the same operator with the same technique as well as syringe with 27- needle gauge (Beehive Solutions Ltd, Ilford, Essex, UK).

\section{Study Outcome:}

Pain assessment was evaluated by subjective pain assessment during local anesthesia injection by means of Wong-Baker faces PRS (29). It was scored from $0-10$ as 0 is very happy and feels no pain and 10 are very painful. Each child was trained to use the scale first by modeling then by asking each participant to think of the last time she/he had felt something painful in order to select the facial expression that best represented his/her experience of discomfort. Pain

\section{Statistical analysis}

Data was analyzed using IBM SPSS statistical software (version 25) (IBM Corporation, NYC, USA). The level of significance was set at $\mathrm{P} \leq 0.05$. Percent difference between the two methods (DV tool and 20\% benzocaine gel) was evaluated using Wilcoxon-signed rank test (30). MannWhitney test (31) was used to evaluate gender influence on pain scores.

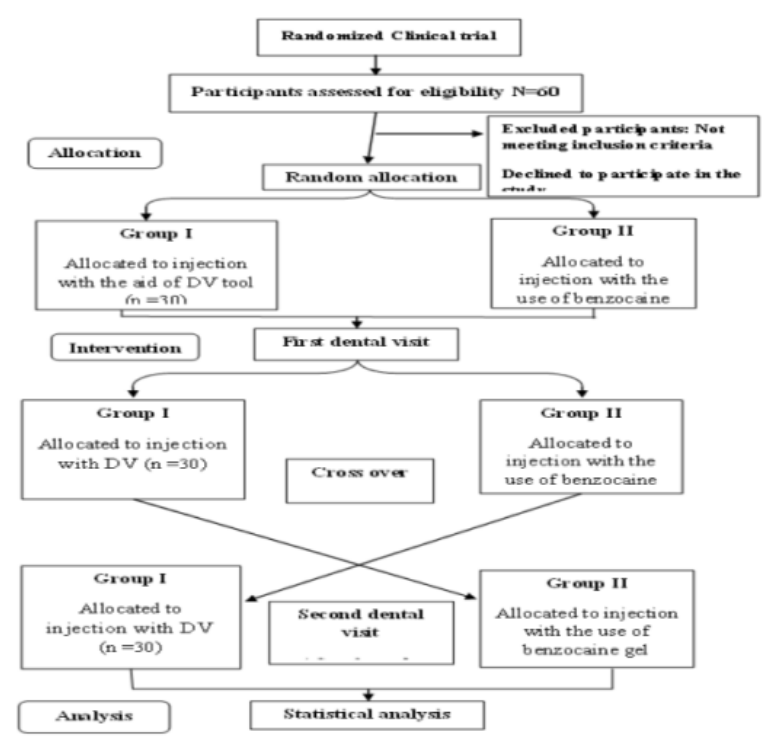

Figure 1 "A CONSORT diagram showing the study protocol”.

\section{RESULTS}

This study included a total of 60 patients of mean age $=5.82$ \pm 0.77 with 30 males and 30 females. Evaluation of inferior alveolar injection pain according to Wong-Baker faces PRS revealed a significant difference between $\mathrm{DV}$ and benzocaine gel $(\mathrm{p}<0.001)$; the pain level in DV injection group recorded lower values compared to benzocaine gel group with percent difference $78.43 \% \pm 0.32$ less pain for DV group (Table 1), and in term of application order no significant difference was reported between the two methods of pain reduction (Table 2). However, regarding gender influence, Wong-Baker faces PRS showed no significant difference in the pain scores of DV and benzocaine gel (Table 3).

Table 1 Pain Intensity using Wong Baker faces PRS in the 2 Study Interventions

\begin{tabular}{|c|c|c|}
\hline \multicolumn{3}{|c|}{$\begin{array}{c}\text { Mean } \pm \text { SD } \\
\text { (Confidence intervals) }\end{array}$} \\
\hline DentalVibe Tool & $\begin{array}{c}\text { Benzocaine gel } \\
20 \%\end{array}$ & $\begin{array}{c}\text { Percent } \\
\text { Difference }\end{array}$ \\
\hline $\begin{array}{l}0.80 \pm 1.34 \\
(0.45,1.15)\end{array}$ & $\begin{array}{l}2.60 \pm 3.22 \\
(1.77,3.43)\end{array}$ & $-78.43 \pm 0.32$ \\
\hline \multicolumn{3}{|c|}{$\begin{array}{c}\text { * Statistically significant at } \mathrm{p} \leq 0.05 \\
\text { Wilcoxon signed-rank test was used } \\
\text { ercent Difference: Intervention DV compared to } \\
\text { Benzocaine gel }\end{array}$} \\
\hline
\end{tabular}

Table 2 Comparison of Wong Baker faces PRS Between the 2 Study Interventions According to the Initial Intervention 


\begin{tabular}{|l|l|l|l|}
\hline & $\begin{array}{l}\text { DentalVibe } \\
\text { Tool }\end{array}$ & $\begin{array}{l}\text { Benzocaine } \\
\text { gel 20\% }\end{array}$ & $\begin{array}{l}\text { P } \\
\text { Value } \\
\boldsymbol{a}\end{array}$ \\
\hline $\begin{array}{l}\text { Starting with } \\
\text { DentalVibe mean } \\
\pm \text { SD } \\
\text { (Confidence } \\
\text { intervals) }\end{array}$ & $\begin{array}{l}0.73 \pm 1.44 \\
(0.20,1.27)\end{array}$ & $\begin{array}{l}2.40 \pm 3.46 \\
(1.11,3.69)\end{array}$ & $0.004^{*}$ \\
\hline $\begin{array}{l}\text { Starting with } \\
\text { Benzocaine gel } \\
\text { mean } \pm \text { SD } \\
\text { (Confidence } \\
\text { intervals) }\end{array}$ & $\begin{array}{l}0.87 \pm 1.25 \\
(0.40,1.33)\end{array}$ & $2.80 \pm 3.00$ & $0.001^{*}$ \\
\hline P Value $\boldsymbol{b}$ & $0.468,3.92)$ & \\
\hline $\begin{array}{l}\text { * Statistically significant at } \mathrm{p} \leq 0.05 \\
\text { a Wilcoxon signed-rank test was used } \\
\text { b Mann- Whitney U test was used }\end{array}$ & 0.34 & \\
\hline
\end{tabular}

Table 3 Wong Baker faces PRS values difference in males and females

\begin{tabular}{|l|l|l|l|l}
\hline \multicolumn{2}{|l|}{} & $\begin{array}{l}\text { Males } \\
\text { mean } \pm \text { SD } \\
\text { (Confidence } \\
\text { intervals) }\end{array}$ & $\begin{array}{l}\text { Females } \\
\text { mean } \pm \text { SD } \\
\text { (Confidence intervals })\end{array}$ & P Value \\
\hline $\begin{array}{l}\text { DentalVibe } \\
\text { Tool }\end{array}$ & $\begin{array}{l}\text { Wong-Baker } \\
\text { faces PRS }\end{array}$ & $\begin{array}{l}0.53 \pm 1.04 \\
(0.24,1.06)\end{array}$ & $\begin{array}{l}1.07 \pm 1.55 \\
(0.38,1.62)\end{array}$ & 0.15 \\
\hline Benzocaine & Wong-Baker & $2.47 \pm 3.51$ & $2.73 \pm 2.95$ & \\
\hline gel 20\% & faces PRS & $(1.51,4.02)$ & $(1.29,3.48)$ & 0.33 \\
\hline
\end{tabular}

Mann- Whitney U test was used

\section{DISCUSSION}

The main objective of this randomized clinical trial was to assess the effectiveness of using DV tool on pain perception in comparison to $20 \%$ benzocaine gel application during IANB administration experienced by boys and girls. In the present study, pain perception was assessed by the children using the Wong-Baker Faces PRS, because it was the preferred method when children were given a choice among all self-reported pain scales (5). The Wong-Baker faces PRS validity has been previously proven for the assessment of pain intensity in children aged 4 to 12 years (5). The results of this study revealed that vibration applied using the DV has significantly reduced the self-reported pain values during IANB compared to benzocaine gel application. These findings are supported by previous clinical trials of Ching et al (20) and Dak-Albab et al (21). By contrast, Roeber et al (32) reported that the mucosal vibration applied during local anesthesia injection did not reduce the pain. This contradiction may be due to the small area of vibration applied by VibraJect, which didn't activate the mechanical receptors in the injection site unlike the vibrations applied by DV. Also, the design of the device was an important factor in pain perception for applying local anesthesia. As the VibraJect needle was connected to the device, while in use for injection, the vibration stimuli could complicate the injection process. Additionally, the presentation of the device with a needle could be frightening for pediatric patients. In contrast, the DV looks like a dental mirror and has a toy head that comes in different animal shapes, so it can be applied comfortably, especially in pediatric patients (33). Besides, the current results contradict the findings of Sermet et al (10), Raslan and Masri (34) in their clinical trials regarding effectiveness of DV, which may be due to lack of standardization, as they worked on both arches, and it is known that anatomical location of intraoral injection is recognized as one of the most important determinants causing injection pain in the clinical practice of dentistry (35, 36). But, in this present study the mandibular nerve block injection was solely evaluated for pain perception. Moreover, in terms of application order, there was no statistically significant difference between the pain scores indicating that the order of application did not have a confounding influence on the pain experienced. In both orders, the pain level was less for DV method. Regarding the gender influence, the current study found no significant interaction between gender and pain perception occurring which agreed with the findings of Bagherian et al (37) and Sermet et al (10), but this contradicts the finding of Eli (38) and Perry et al (9) who found that females had a statistically significant more pain experience. The contradiction with our results could be due to age range difference which was mainly adults in their study and that may affect the results as stressful situations caused more varied reactions in this agegroup compared to younger children (39). The null hypothesis was partially accepted, as the results revealed that DV reduced IANB pain compared to the use of benzocaine gel thus rejecting the null hypothesis, while there was no difference between girls and boys in pain perception thus accepting the null hypothesized. A limitation of this study was that patients could not be blinded due to the physical vibrational stimulation experienced by them when using the DV.

\section{CONCLUSIONS}

1. The DV injection system reduced pain associated with IANB in pediatric dental patients.

2. Gender has no influence on pain perception experienced by pediatric dental patients.

\section{CONFLICT OF INTEREST}

The authors declare that they have no conflicts of interest 


\section{REFERENCES}

1. Craig K. Emotional aspects of pain. In: WALL PD, R M, eds. Textbook of pain. $2^{\text {nd }}$ ed. London: Churchill Livingston; 1989:220-30.

2. Armfield JM, Heaton L. Management of fear and anxiety in the dental clinic: a review. Aust Dent J. 2013;58:390407.

3. Shim Y-S, Kim A-H, Jeon E-Y, An S-Y. Dental fear \& anxiety and dental pain in children and adolescents; a systemic review. J Dent Anesth Pain Med. 2015;15:53-61.

4. Weisenberg M. Pain and pain control. Psychol Bull. 1977;84:1008-44.

5. Tomlinson D, von Baeyer CL, Stinson JN, Sung L. A Systematic Review of Faces Scales for the Self-report of Pain Intensity in Children. Pediatrics. 2010;126:e1168-e98.

6. Von Baeyer CL. Children's self-reports of pain intensity: scale selection, limitations and interpretation. Pain Res Manag. 2006;11:157-62.

7. Eli I, Bar-Tal Y, Fuss Z, Korff E. Effect of biological sex differences on the perception of acute pain stimulation in the dental setting. Pain Res Manag. 1996;1:201-6.

8. Fillingim RB, Maixner W. Gender differences in the responses to noxious stimuli. Pain forum. 1995;4:209-21.

9. Perry S, Drum M, Reader A, Nusstein J, Beck M. Effect of Operator and Subject Gender on Injection Pain: A Randomized Double-blind Study. J Endod. 2015;41:1415.

10. Sermet Elbay U, Elbay M, Yildirim S, Kaya E, Kaya C, Ugurluel C, et al. Evaluation of the injection pain with the use of DentalVibe injection system during supraperiosteal anaesthesia in children: a randomised clinical trial. Int J Paediatr Dent. 2016;26:336-45.

11. Mutalik S. How to make local anesthesia less painful. J Cutan Aesthet Surg. 2008;1:37.

12. McDonald RE, Avery DR, Dean JA, Jones JE. Local anesthesia and pain control for the child and adolescent. In: McDonald RE, Avery DR, eds. Dentistry for the Child and Adolescent. $10^{\text {th }}$ ed. St. Louis, Missouri, Elsevier Inc; 2011:241-52.

13. Veneva ER, Belcheva AB. Local anesthesia in pediatric patients-a review of current and alternative methods, devices and techniques. Folia Med. 2018;60:381-8.

14. Tandon S, Kalia G, Sharma M, Mathur R, Rathore K, Gandhi M. Comparative Evaluation of Mucosal Vibrator with Topical Anesthetic Gel to reduce Pain during Administration of Local Anesthesia in Pediatric Patients: An in vivo Study. Int J Paediatr Dent. 2018;11:261.

15. Saxena P, Gupta SK, Newaskar V, Chandra A. Advances in dental local anesthesia techniques and devices: An update. Natl J Maxillofac Surg. 2013;4:19-24.

16. Melzack R, Wall PD. Pain mechanisms: a new theory. Science. 1965;150:971-9.

17. Dickenson AH. Editorial I: Gate Control Theory of pain stands the test of time. BJA; 2002;88:755-7.

18. Sufka KJ, Price DD. Gate control theory reconsidered. Brain and Mind. 2002;3:277-90.
19. Shilpapriya M, Jayanthi M, Reddy VN, Sakthivel R, Selvaraju G, Vijayakumar P. Effectiveness of new vibration delivery system on pain associated with injection of local anesthesia in children. J Indian Soc Pedod Prev Dent. 2015;33:173.

20. Ching D, Finkelman M, Loo CY. Effect of the DentalVibe injection system on pain during local anesthesia injections in adolescent patients. Pediatr Dent. 2014;36:51-5.

21. Dak-Albab R, Al-Monaqel MB, Koshha R, Shakhashero H. A comparison between the effectiveness of vibration with Dentalvibe and benzocaine gel in relieving pain associated with mandibular injection: a randomized clinical trial. APIC. 2016;20:43-9.

22. Frankl S. Should the parent remain with the child in the dental operatory? J Dent Child. 1962;29:150-63.

23. Killeen PR. An alternative to null-hypothesis significance tests. Psychol sci. 2005;16:345-53.

24. Daniel WW, Cross CL. Estimation. In: Brady J, ed. Biostatistics; a foundation for analysis in the health sciences $10^{\text {th }}$ ed. Hoboken, NJ: Wiley, 2018:143-88.

25. Pannucci CJ, Wilkins EG. Identifying and avoiding bias in research. Plast Reconstr Surg. 2010;126:619.

26. Faul F, Erdfelder E, Lang A-G, Buchner A. G* Power 3: A flexible statistical power analysis program for the social, behavioral, and biomedical sciences. BRM. 2007;39:175-91.

27. Schwartz, Steven, and Ari Kupietzky. local anesthesia. In: Wright GZ , Kupietzky A,eds. Behavior Management in Dentistry for Children $2^{\text {nd }}$ ed. Ames, Iowa: Wiley, 2014:107-24.

28. Nusstein JM, Beck M. Effectiveness of $20 \%$ benzocaine as a topical anesthetic for intraoral injections. Anesth prog. 2003;50:159.

29. Wong DL, Baker CM. Pain in children: comparison of assessment scales. Pediatr Nurs. 1988;14:9-17.

30. Wilcoxon F, Katti S, Wilcox RA. Critical values and probability levels for the Wilcoxon rank sum test and the Wilcoxon signed rank test. Selected tables in mathematical statistics. 1970;1:171-259.

31. McKnight PE, Najab J. Mann-Whitney U Test. In: Weiner IB, Craighead WE eds. The Corsini encyclopedia of psychology. $4^{\text {th }}$ ed. John Wiley \& Sons, Inc; 2010:1-.

32. Roeber B, Wallace DP, Rothe V, Salama F, Allen KD. Evaluation of the effects of the VibraJect attachment on pain in children receiving local anesthesia. Pediatr Dent. 2011;33:46-50.

33. Ungor C, Tosun E, Dayisoylu EH, Taskesen F, Senel FC. The effects of vibration on pain and anxiety during local anesthesia administration. JSM Dent. 2014;2:1022.

34. Raslan N, Masri R. A randomized clinical trial to compare pain levels during three types of oral anesthetic injections and the effect of Dentalvibe((R)) on injection pain in children. Int J Paediatr Dent. 2018;28:102-10.

35. Kaufman E, Epstein JB, Naveh E, Gorsky M, Gross A, Cohen G. A survey of pain, pressure, and discomfort 
induced by commonly used oral local anesthesia injections. Anesth prog. 2005;52:122-7.

36. Aminabadi NA, Farahani RMZ, Oskouei SG. Sitespecificity of pain sensitivity to intraoral anesthetic injections in children. J Oral Sci. 2009;51:239-43.

37. Bagherian A, Sheikhfathollahi M. Children's behavioral pain reactions during local anesthetic injection using cotton-roll vibration method compared with routine topical anesthesia: A randomized controlled trial. Dent Res J. 2016;13:272-7.
38. Eli I, Baht R, Kozlovsky A, Simon H. Effect of gender on acute pain prediction and memory in periodontal surgery. Eur J Oral Sci. 2000;108:99-103.

39. Hägglöf B. Psychological reaction by children of various ages to hospital care and invasive procedures. Acta paediatrica. 1999;88:72-8. 